\title{
Formação tecnocientífica nas políticas educacionais para 0 ensino médio: uma perspectiva curricular
}

\author{
Roberto Rafael Dias da Silva \\ Universidade Federal da Fronteira do Sul
}

\section{Resumo}

0 presente estudo inscreve-se no campo dos Estudos Curriculares e objetiva estabelecer um diagnóstico crítico das estratégias políticas que operam na inserção de temas tecnocientíficos nas políticas curriculares para o ensino médio. A partir de uma análise documental, indica-se uma dupla tendência formativa na composição curricular para esta etapa da educação básica: por um lado, uma ênfase no despertar talentos, visando ao desenvolvimento econômico; por outro, uma abordagem mais cidadã focada na democratização do acesso aos saberes tecnocientíficos.

Palavras-chave: Políticas curriculares. Tecnociência. Ensino médio. 


\section{The technoscientific question in education policies for secondary education: a curricular perspective}

This study falls within the field of Curriculum Studies and aims at establishing a critical diagnosis of the policy strategies that come into play in the inclusion of technoscientific issues in curriculum policies for secondary education. Based on a documentary analysis, it points to a dual tendency in training, in composing curricula for this stage of education: on the one hand, an emphasis on awakening talents in order to promote economic development, on the other, a more citizen-focused approach focused on democratizing access technoscientific knowledge.

Keywords: Curriculum Policies. Technoscience. High School. Secondary Education.

\section{Formación tecnocientífica en la política educativa de la Escuela Secundaria: una perspectiva curricular}

Este estudio se enmarca dentro del campo de los estudios curriculares y tiene por objeto establecer un diagnóstico de las estrategias políticas que operan en la inserción de temas tecnocientíficos en la política curricular para la educación secundaria. Desde un análisis documental indica una doble tendencia formativa en la composición de los currículos para esta etapa de la educación: por un lado, el énfasis en el despertar de talentos orientados al desarrollo económico, por el otro, un enfoque más ciudadano centrado en la democratización del acceso al conocimiento tecnocientífico.

Palabras-clave: Políticas curriculares. Tecnociencia. Escuela Secundaria. 


\section{Introdução}

0 desafio que mobiliza a escrita deste texto é problematizar as questões tecnocientíficas presentes nas atuais políticas curriculares para o ensino médio. Consideramos pertinente estabelecer um diagnóstico crítico das políticas curriculares implementadas em nosso País, em suas interfaces com o campo da tecnociência, fabricando um determinado campo de práticas para as escolas públicas. De imediato, porém, importa reiterar que não pretendemos produzir um estudo especializado no campo das políticas científicas; mas, antes disso, tomá-las como contexto para uma leitura diagonal da produção dos currículos escolares para o ensino médio em nosso País. Nossa abordagem sugere um olhar atento para determinadas relações sociais que estabelecem uma centralidade dos valores tecnocientíficos nas pautas formativas das sociedades de nosso tempo.

0 ensino médio, em nosso País, tem sido alvo de um conjunto de reformas ao longo da última década, visando ampliar seu processo de democratização (Krawczyk, 2011). Em geral, tais demandas democratizadoras são decorrentes de duas questões políticas, a saber: de um lado, as pressões dos setores populares que buscam acessar esse espaço formativo; de outro lado, "a necessidade de tornar o país mais competitivo no cenário econômico internacional" (Krawczyk, 2011, p. 755). Nas condições da nomeada sociedade do conhecimento, aspira-se a que a formação dos jovens estabeleça maior aproximação com as questões de seus interesses, com os avanços tecnológicos e com o mercado profissional. Dessas condições, emergem novas políticas educacionais destinadas a tornar os currículos escolares para o ensino médio mais atraentes e flexíveis, de forma a atender às aspirações da sociedade do conhecimento. Nessa gramática formativa, “o conhecimento também é identificado como o capital mais importante do trabalhador nas novas formas de produção". (Krawczyk, 2011, p. 757)

Multiplicam-se, então, novos direcionamentos nas políticas curriculares para o ensino médio, em suas diferentes orientações. Apresenta-se como um consenso nas novas Diretrizes Curriculares Nacionais para o Ensino Médio (2012), no Programa Ensino Médio Inovador (2009) ou mesmo no recente Pacto Nacional pelo Fortalecimento do Ensino Médio (2014) a busca pela “definição de uma grade curricular mais atrativa e flexível, capaz de atrair o aluno para o ensino médio e combater a repetência e a evasão" (Moehlecke, 2012, p. 53). Privilegiando a composição de políticas curriculares mais atraentes para estas novas condições, uma das temáticas que adquire centralidade é a aproximação dos currículos escolares com as novas condições tecnocientíficas emergentes 
na contemporaneidade. (Silva, 2012)

Acerca das questões tecnocientíficas, importa reiterar que, ao longo da última década, intensificaram-se os programas de investimento na área da ciência e da tecnologia no Brasil (Silva, 2012). 0 debate sobre a questão ainda é bastante recente, visto que a própria criação de um Ministério que coordene as políticas nacionais deu-se apenas em 1985. Mesmo assim, vale assinalar que a busca do desenvolvimento nacional, mediante a promoção de valores científicos, é recorrente desde o início do século XX. Entretanto, podemos constatar que o direcionamento destas políticas para o âmbito dos currículos escolares, com ampla capacidade de financiamento público e privado, deuse somente na primeira década do novo século. De modo exemplar, no que tange aos incentivos internacionais para a questão, podemos citar que "a educação tecnocientífica (sobretudo no ensino médio) tem se constituído como um dos principais campos de investimento das atividades atuais da UNESCO" (Silva, 2012, p. 56). A busca pela inserção da referida temática nos currículos escolares, em geral, é mobilizada por duas racionalidades políticas, distintas e complementares: de um lado privilegiando a popularização do acesso à ciência, de outro a contribuição para o desenvolvimento econômico do País. Em comum a ambas as racionalidades políticas encontramos a espera de resultados futuros, na qual um país efetiva estes investimentos "à espera dos ovos de ouro" (Unesco, 2005, p. 4), como sugere um relevante documento dessa organização internacional.

Metodologicamente, o estudo do qual este artigo é derivado trata de uma análise documental que toma como materialidade empírica um conjunto de textos curriculares produzidos na última década. Foram selecionados documentos publicados por diferentes atores políticos, tanto em nível internacional (como a Unesco e o Banco Mundial), quanto em nível local (como - Ministério da Educação, o Ministério da Ciência e Tecnologia e as secretarias estaduais). Os documentos foram selecionados a partir de seu direcionamento para o ensino médio, assim como de sua ênfase na inserção de temáticas ligadas ao desenvolvimento tecnocientífico nesta etapa da educação básica.

Sob tais condições, ao revisar algumas políticas curriculares para o ensino médio, notamos uma dupla tendência formativa na composição de seus documentos: por um lado, uma ênfase no despertar talentos, visando ao desenvolvimento econômico; por outro, percebemos uma abordagem mais cidadã na democratização do acesso aos saberes tecnocientíficos. Isso expressa os tensionamentos de um cenário de hipermodernização do mundo, o qual sociologicamente exploraremos na primeira seção do texto. Tal cenário cultural produz significativo impacto nas reconfigurações contemporâneas 
do Estado, associadas à mobilização de novas políticas formativas para os currículos escolares do ensino médio, do que trataremos na segunda seção. Por fim, ao examinarmos alguns documentos curriculares para o ensino médio, indicamos a mobilização de estratégias bioeconômicas sobre a população brasileira, que tendem a multiplicar os investimentos políticos neste nível formativo e a tomar a educação tecnocientífica enquanto uma intensificação das formas de competitividade.

\section{"Cultura-mundo" e hipermodernização do mundo: um diagnóstico sociológico}

$\mathrm{Na}$ atualidade temos encontrado diferentes modos de descrever e caracterizar a sociedade contemporânea. Inúmeras formas como as noções de pós-modernidade (Lyotard, 2009), modernidade líquida (Bauman, 2001), novo capitalismo (Sennett, 2006) ou capitalismo cognitivo (Corsani, 2003), dentre outras, geralmente tendem a associar mudanças nos modos de vida produzidos desde a Modernidade, engendrados recentemente pelos fenômenos da globalização, pelo predomínio do capitalismo neoliberal ou mesmo pelo declínio dos valores e modos de vida tradicionais. Um dos lugares teóricos que tem conseguido mobilizar esforços para essa tarefa é a sociologia francesa contemporânea, à qual atribuiremos ênfase nesse diagnóstico ao pensamento recente de Gilles Lipovetsky. (Lipovetsky, 2004; Lipovetsky; Serroy, 2011)

De acordo com o pensador, diferentemente do que se vislumbrava no final da década de 1970 com o conceito de pós-modernidade - na arte, na cultura, na filosofia -, a contemporaneidade não se direcionou para um remate dos valores do mundo moderno. Em sua leitura, a própria expressão “pósmoderno" apresentava-se de forma vaga uma vez que "era evidentemente uma modernidade de novo gênero a que tomava corpo, e não uma simples superação daquela anterior" (Lipovetsky, 2004, p. 52). 0 que parece encaminhar-se dessa análise é que, hodiernamente, experienciamos uma "era do hiper", uma modernidade elevada às suas potências máximas.

Ao clima de epílogo segue-se uma sensação de fuga para adiante, de modernização desenfreada, feita de mercantilização proliferativa, de desregulamentação econômica, de ímpeto técnico-científico, cujos efeitos são tão carregados de perigos quanto de promessas. Tudo foi muito rápido: a coruja de Minerva anunciava o nascimento do pós-moderno no momento mesmo em que se esboçava a hipermodernização do mundo. (Lipovetsky, 2004, p. 53) 
As características de nossa presente modernidade atribuem visibilidade ao predomínio de valores individualistas, radicalizando o culto à concorrência e às promessas da inovação tecnocientífica. Segundo Lipovetsky (2004), ingressamos em um período de "hipermodernidade". Nas palavras do autor, "eleva-se uma segunda modernidade, desregulamentadora e globalizada, sem contrários, alicerçando-se essencialmente em três axiomas constitutivos da própria modernidade anterior: o mercado, a eficiência técnica, o indivíduo" (Lipovetsky, 2004, p. 54). Sob as condições orientadoras desses três axiomas, a hipermodernidade apresenta-se como grade de inteligibilidade para explicarmos questões específicas da sociedade do nosso tempo.

Em obra recente, Lipovetsky e Serroy (2011) conduzem esse debate para o campo cultural, assinalando que a predominância dos valores de uma sociedade hipermoderna fabricou condições para a emergência de uma "cultura-mundo". De imediato, os autores destacam que o uso que realizam do conceito de cultura não supõe "um sistema completo e coerente de explicação do mundo" (Lipovetsky; Serroy, 2011, p. 78). Tal argumento justifica-se pelo fato de que, na hipermodernidade, a cultura modifica seu estatuto; não mais vinculado a um humanismo universal, mas às condições de um mundo sem fronteiras de capitais. É nesse cenário, de uma cultura reiteradamente globalizada, que os autores passam a falar de "cultura-mundo".

Cultura-mundo significa o fim da heterogeneidade tradicional da esfera cultural e a universalização da cultura mercantil, apoderando-se das esferas da vida social, dos modos de existência, da quase totalidade das atividades humanas. Com a culturamundo, dissemina-se em todo o mundo a cultura da tecnociência, do mercado, do indivíduo, das mídias, do consumo; e, com ela, uma infinidade de novos problemas que põem em jogo questões não só globais lecologia, imigração, crise econômica, miséria do Terceiro Mundo, terrorismo ...) mas também existenciais (identidade, crenças, crise dos sentidos, distúrbios de personalidade ...). A cultura globalitária não é apenas um fato, é, ao mesmo tempo, um questionamento tão intenso quanto inquieto de si mesma. Mundo que se torna cultura, cultura que se torna mundo: uma cultura-mundo. (Lipovetsky; Serroy, 2011, p. 9)

Para explicar mais atentamente, Lipovetsky e Serroy procuram explorar os quatro polos do mundo hipermoderno, instituintes da noção de cultura-mundo. A descrição desses polos implica o reconhecimento de que as mudanças em curso na atualidade não são apenas produtos da "globalização liberal", mas são derivados de diferentes espaços culturais da atualidade. Conforme argumentamos anteriormente, os axiomas do indivíduo, do mercado e da 
tecnociência, em ação articulada, estruturam a fisionomia das novas culturas, demarcando fortemente o desenvolvimento dos processos formativos e das políticas de escolarização.

Problematizando a "cultura-mundo", enquanto um "sistema organizador do mundo", os autores expõem suas diferentes possibilidades de intervenção.

Essas axiomáticas são: o hipercapitalismo, a força motriz da globalização financeira; a hipertecnicização, grau superlativo da universalidade técnica moderna; o hiperindividualismo, concretizando a espiral do átomo individual daí em diante desprendido das coerções comunitárias à antiga; o hiperconsumo, forma hipertrofiada e exponencial do hedonismo mercantil. Essas lógicas em constantes interações compõem um universo dominado pela tecnicização universalista, a desterritorialização acelerada e uma crescente comercialização planetarizada. É nessas condições que a época vê triunfar uma cultura globalizada ou globalista, um cultura sem fronteiras cujo objetivo não é outro senão uma sociedade universal de consumidores. (Lipovetsky; Serroy, 2011, p. 32)

As quatro axiomáticas, descritas e analisadas pelos pensadores franceses, possibilitam-nos a compreensão de questões atinentes ao processo global de implementação das políticas curriculares com foco nos valores tecnocientíficos, em associação ao individualismo e à competitividade. 0 hipercapitalismo, por exemplo, favorece-nos com a visualização de uma onipresença do Homo Economicus, associado a uma expansão da economia para espaços não prioritariamente dessa natureza'. Tal aspecto faz-se possível pois “o triunfo do hipercapitalismo não é apenas econômico, é cultural, tornando-se o esquema organizador de todas as atividades, o modelo geral do agir e da vida em sociedade" (Lipovetsky; Serroy, 2011, p. 38). A ampliação da esfera econômica produz desdobramentos significativos na produção subjetiva dos indivíduos, para a composição das organizações e, direta ou indiretamente, recria/reinventa formas de intervenção para o Estado. Que desdobramentos deste cenário podem ser identificados na composição atual das políticas curriculares para o ensino médio? Ampliaremos esse debate a seguir, procurando dimensioná-lo em algumas perspectivas contemporâneas sobre as políticas educacionais, em geral, e as políticas de currículo, em particular.

1. A expansão da economia para campos prioritariamente não econômicos já era descrita e analisada por Michel Foucault (2008) em seu curso no Còllege de France - Nascimento da Biopolítica - no ano de 1979. 


\section{Estado, políticas formativas e os currículos escolares: tematizações}

Com o advento das formas culturais da cultura-mundo, descritas na seção anterior, podemos verificar também um conjunto de deslocamentos nas formas de planejamento e organização das políticas formativas, delineadas pela reconfiguração do próprio Estado. Nessa direção, experienciamos contemporaneamente uma reconfiguração das formas de governo das políticas, envolvendo uma intensa rearticulação das formas públicas e privadas, a realocação de tarefas e a ampliação das esferas de atuação do Estado. (Ball, 2008). Emergem um conjunto de novos especialistas, institutos de pesquisas e inovação e setores voluntários destinados a ampliar o campo de atuação do Estado. "Portanto, novas vozes e interesses são representados no processo político, e novos nós de poder e influência são construídos e fortalecidos" (Ball, 2013a, p. 177). De acordo com Stephen Ball (2013a), em uma abordagem pluralista, a mobilização desses novos atores conduz a um processo de desconcentração, na qual a ação pública de governo articula-se por entre "hierarquias, mercados e heterarquias" (Ball, 2013a, p. 178)

As ações de governo, gestadas a partir de heterarquias, tendem a favorecer o desenvolvimento de estratégias em rede para o Estado ${ }^{2}$. Nessa compreensão, a heterarquia aciona novas formas organizativas que, direta ou indiretamente, tendem a ampliar o campo de intervenção das estratégias estatais.

Heterarquia é uma forma de organização, algo entre hierarquia e rede, que aproveita diferentes ligações horizontais as quais permitem que diferentes elementos do processo político cooperem (e/ou se completem) enquanto individualmente otimiza diferentes critérios de sucesso. Incorporados nessa mudança, como indicado anteriormente, e de muitas formas fundamentais a ela estão os processos de privatização - endógenos e exógenos. (Ball, 2013a, p. 178)

Com a multiplicação das formas de heterarquia, organiza-se um deslocamento das formas de "governo" para as de "governança" (Ball, 2008). Novas técnicas de governo são estruturadas - parcerias, regimes mistos, intersetorialidade - de modo experimental e, ao mesmo tempo, estratégico. Amplia-se a capacidade de governo e seu potencial de legitimidade. Segundo Ball (2013a, p.180), “isso é um meio de governar por meio da governança ou o exercício da metagovernança". A governança expõe a pluralidade e a complexidade das formas de governo.

2. Sob outra perspectiva, abordagens como as de Giddens (1991) e Castells (1999) assinalavam a configuração de um Estado atuando em rede. 
Entretanto, ao colocar e discutir essas mudanças, preciso esclarecer que não estou sugerindo que isso envolva um abandono pelo Estado de sua capacidade de conduzir a política, isso não é um "esvaziamento" do Estado; antes, é uma nova modalidade de poder público, agência e ação estatal e, na verdade, uma nova forma de Estado. Ou seja, a realização de fins políticos por diferentes meios. (Ball, 2013a, p. 180)

A referida mudança nos meios de intervenção política também é indicada por Popkewitz (2011) ao examinar as perspectivas do contrato social e dos sistemas de parceria nas recentes políticas curriculares. A produtiva intersecção entre contrato social e as parcerias propõe-se a redimensionar as formas de gestão da escola, assumindo a descentralização como uma forte estratégia de intervenção. A emergência de novas formas de controle social, por meio da governança pública, traz como um dos seus impactos mais significativos as medidas de responsabilização dos indivíduos, junto ao postulado da "salvação pelas reformas". Ainda que coloquem em seu horizonte as questões da equidade e da justiça social, "as novas abordagens da gestão pública não renovam apenas o contrato social, elas encarnam também um novo conjunto de relações que investe o indivíduo de capacidades e de habilidades particulares". (Popkewitz, 2011, p. 237)

A salvação pela reforma, tal como é descrita pelo pesquisador estadunidense, opera na mobilização dos sistemas de regulação da escola pública, privilegiando as noções de desempenho, de excelência e de eficácia. Com isso, tendem a ressituar os processos de decisão sob outros modos de aproximação com a sociedade civil, dedicando atenção especial às questões da parceria e da coletividade. A coletividade, conforme o autor, apresenta-se como uma "metáfora sedutora", na medida em que se aproxima dos indivíduos "a fim de individualizar o engajamento moral e ético da democracia". (Popkewitz, 2011,p. 240)

A coletividade acentua a ideia do cidadão autônomo (parceria), da qual é constituído o contrato social para o bem-estar coletivo. Ela está também no interior do discurso sobre a diversidade, a diferença e o multiculturalismo, sem contar que é evocada nas diferentes reformas americanas que pregam a microgestão, a colaboração entre a escola e a casa e as discussões que transformam a classe em uma "comunidade de aprendizagem". (Popkewitz, 2011, p. 240)

A disposição do conceito de coletividade, em uma perspectiva neoliberal, sugere uma ética baseada nos indivíduos lem seu desempenho, seu protagonismo, seu voluntariadol, produzindo significativas modalidades de 
regulação da vida ${ }^{3}$. Aproximando-se das teorias pedagógicas contemporâneas, Popkewitz sugere que a própria "alma" da escola foi deslocada. "A alma da escola moderna não é a alma religiosa da pós-vida cristã, mas antes a de uma individualidade ordenada pelas disposições, pelas sensibilidades e pela consciência, que fazem do ator civilizado uma pessoa capaz de evoluir numa cultura e numa economia globais" (Popkewitz, 2011, p. 243). As formas de contrato e de parceria, típicas das formas de governança de nosso tempo, reinventam modalidades subjetivas e modos de compreender a pedagogia de nossa época.

Os modos de atuação do Estado explicitados na forma de heterarquias (Ball, 2013a), associados às formas de governo mobilizadas nos contratos e parcerias das políticas neoliberais (Popkewitz, 2011), compõem ancoragens sociais para o exame das políticas curriculares brasileiras. Articulamos a essas abordagens a leitura desenvolvida por Licínio Lima (2012), importante sociólogo português, ao informar o caráter utilitarista das propriedades do conhecimento - especialmente associado às abordagens da "aprendizagem ao longo da vida". O educar para a empregabilidade, o empreendedorismo educacional ou o "aprender para ganhar, conhecer para competir" são grandes lemas das políticas de conhecimento escolar ${ }^{4}$ inspiradas nessa lógica.

Com efeito, a apologia da aprendizagem individual parece correlativa das tendências para a individualização das relações de trabalho e, no limite, aponta para o modelo do "eu" empresarial, a realização mais radical e conseguida do ideal da "empresa flexível", capaz de substituir o trabalho assalariado pelo trabalho independente e o trabalhador pelo prestador de serviços, empresário e gestor de sua própria carreira. Como se os "ambientes de aprendizagem", as "oportunidades de aprendizagem", e de vida, fossem iguais para todos e não fossem influenciadas por relações de poder, de classe, de gênero, etc. (Lima, 2012, p. 33)

0 referido cenário auxilia-nos a perceber uma mudança paradigmática situada na transição da educação para a aprendizagem, do social para o

]3. Popkewitz (2010, p.357) sugere que noções consolidadas na pedagogia contemporânea, como a resolução de problemas como estratégia privilegiada, associam-se a modos de vida que "diferenciam, dividem e estabelecem diferenças sobre como cada um vive e deve viver".

4. Simons e Masschelein (2013, p.94), de outra perspectiva teórica, argumentam que as expressivas modalidades de aprendizagem ao longo da vida podem indicar um processo de "governamentalização da aprendizagem". 
individual ${ }^{5}$. Mais que isso, sugere que somente os próprios indivíduos sejam dotados de racionalidade específica "para desenhar notas individuais ótimas de aprendizagem, detendo os recursos indispensáveis à construção dos agora denominados "portfólios de competências'" (Lima, 2012, p. 35). As formas de controle policêntricas - heterárquicas, conforme Ball (2013a) movem-se na busca de novos protagonismos entre o Estado, o mercado e as comunidades. De acordo com Lima, ao analisar as políticas da União Européia, com foco na empregabilidade e na flexibilidade, emerge uma nova fórmula regulativa: "aprender para ganhar (learning for earning) é o nome do jogo da aprendizagem ao longo da vida no século XXI". (Lima, 2012p. 41)

Tal como argumentamos nesta seção, as políticas curriculares contemporâneas são produzidas mediante novos dispositivos de regulação da vida coletivab. Sob as condições de consolidação de um "hipercapitalismo", sustentado pelas formas de uma "cultura-mundo" (Lipovetsky; Serroy, 2011), as políticas passam a ancorar-se em novos espaços e a agir de acordo com outros arranjos de governo. A transição das formas de governo para as de governança, associadas a uma atuação em rede do Estado (Ball, 2008; 2013a; 2013b), à emergência das novas formas de contrato de parceria (Popkewitz, 2010; 2011) e à predominância de visões utilitaristas para o conhecimento (Lima, 2012), fabrica novos delineamentos para a análise teórica do campo das referidas políticas. Entretanto, tal diagnóstico abre a possibilidade de um conjunto de novas modalidades de análise crítica, assim como nos impulsiona a fabricar formas agonísticas de reação política e de produção de alternativas. A seguir, sistematizaremos alguns delineamentos das atuais políticas curriculares para o ensino médio focadas na educação tecnocientífica, indicando sua tendência em atribuir centralidade aos valores de uma sociedade hipercapitalista, centradas no indivíduo e nas formas de competitividade pelo mercado. Para analisar esse conjunto de documentos, faremos uso do conceito de "bioeconomia", produzido pelo economista italiano Andrea Fumagalli (2010). O referido conceito apresenta intensa potencialidade analítica para examinarmos as relações entre ciência, tecnologia e sociedade na atualidade.

5. Em estudo recente (Silva, 2013), procuramos constituir um diagnóstico preliminar das políticas de escolarização produzidas nas tramas políticas e econômicas do estágio atual do desenvolvimento capitalista, demarcando que, hodiernamente, predominam tecnologias otimizadoras.

6. Em outro texto (Silva; Silva, 2012), prolongamos esse diagnóstico examinando especificamente as estratégias políticas que regulam a implementação no Brasil de dois programas governamentais, a saber: os programas Mais Educação e Ensino Médio Inovador. 


\section{Educação tecnocientífica no ensino médio: entre a cidadania e o desenvolvimento econômico}

Considerando a predominância dos aspectos referentes a uma hipermodernização do mundo (Lipovetsky, 2004), aproximada de uma ressignificação das formas de intervenção política (Ball, 2013a), podemos inferir que a centralidade dos valores tecnocientíficos nas políticas curriculares para o ensino médio esteja vinculada às próprias mudanças do capitalismo. Segundo a narrativa de Fumagalli (2010), o trabalho industrial não ocupa mais a referência das sociedades de nosso tempo, uma vez que a produção material não exerce centralidade na atual configuração capitalista. Conforme o autor, o conhecimento tornou-se "o pivô que move a metamorfose do capitalismo" (Fumagalli, 2010, p. 259), e, dessa forma, falar de conhecimento implica situálo em outro tipo de produção - a imaterial.

Seguindo a reflexão proposta pelo economista italiano, a produção imaterial não se constitui como o oposto da produção industrial (fordista).

Produção imaterial que não se define como tal somente em oposição à produção material, física e tangível do capitalismo industrial-fordista, senão que é intrinsecamente assim na medida em que se nutre e se fundamenta sobre a prática da linguagem enquanto elemento constituinte do conjunto do processo econômico. Encontramos formas e modalidades imateriais de produção inclusive quando a produção é completamente material. (Fumagalli, 2010, p. 259)

0 principal deslocamento apresentado pelo autor está na inserção da prática da linguagem como parte do processo econômico. Essa modificação introduz novas significações para a relação capital-trabalho, bem como reconfigura as formas de exploração capitalista sobre os trabalhadores. (Corsani, 2003). A esse conjunto de modificações alguns autores nomeiam como "capitalismo cognitivo". (Corsani, 2003). O que importa destacar neste momento é a perspectiva de que tal configuração capitalista é regida por um movimento de "acumulação bioeconômica" (Fumagalli, 2010, p. 260). Diferentemente de estabelecer uma defesa dos pressupostos do capitalismo cognitivo, interessanos aqui situar o estado de forças no qual a tecnociência é valorada e produzida enquanto uma temática curricular.

Quais significados emergem desse processo bioeconômico de produção? Que diferenciações se tornam acentuadas em relação às condições produtivas anteriores? Com o advento das condições do capitalismo cognitivo, o processo de produção, em suas diferentes modalidades, não se baseia mais 
exclusivamente na força física dos sujeitos, nas suas horas de trabalho ou no potencial de lucratividade de seu trabalho. Na medida em que a produção se torna imaterial, “o processo de acumulação se baseia sobre, e toma a substância de, as faculdades vitais dos indivíduos através de uma estrutura reticular de cooperação social. Podemos dizer que o próprio conhecimento é a expressão da bios" (Fumagalli, 2010, p. 260). Com isso, é a própria vida dos indivíduos que dá forma ao processo bioeconômico de acumulação.

Em outras palavras, o ato de acumulação pressupõe a existência de um dispositivo de poder sobre as atividades essenciais com o fim de transformá-las em relações econômicas produtivas. Desde este ponto de vista, a bioeconomia é o aspecto complementar e simétrico da biopolítica: se por biopolítica se entende a capacidade de ação de um dispositivo de controle social e jurídico, a bioeconomia é seu análogo em relação com os mecanismos de produção, acumulação e redistribuição. (Fumagalli, 2010, p. 260)

Acompanham essa discussão outros sentidos para a noção marxiana de capital. A partir das releituras do marxismo feitas pelo movimento operaísta italiano, o referido conceito deixa de ser entendido como uma "substância", sendo situado como uma "relação". Supor que o capital é uma relação implica, segundo Fumagalli, duas constatações: primeiro, que o capital se institui a partir de relações de poder; segundo, que "o capital não pode prescindir da subjetividade do explorado" (Fumagalli, 2010, p. 264). Disso pode derivar a perspectiva de que as subjetividades integram o processo de acumulação bioeconômico de forma ativa. Nas palavras do autor, nestas condições “a relação social representada pelo capital tende a transmutar-se de relação de força de trabalho e máquina, para relação entre mente e corpo, cérebro e coração, ou a converter-se em algo interno ao ser humano. Mas, longe de ser o capital que se humaniza, são as vidas dos indivíduos, com suas múltiplas singularidades e diferenças, que se tornam capitalizáveis". (Fumagalli, 2010, p. 264)

A imaterialização do trabalho produz novas estratégias sobre as subjetividades. Marazzi (2009) argumenta que os novos arranjos de poder dessa sociedade poderiam também ser caracterizados como "biocapitalismo", um capitalismo da inovação permanente e da flexibilidade. "O biocapitalismo põe a vida no centro do crescimento econômico. A própria vida, a vida nua, se torna fonte de valor, ou melhor, um mais-valor absoluto que não é reconhecido pelo capital e, portanto, não é pago". (Marazzi, 2009, p. 11)

Assim, podemos dimensionar os diferentes modos pelos quais a tecnociência adquire centralidade nas políticas curriculares para o ensino médio e se 
torna regida por um conjunto de tecnologias de governo que privilegiam a intensificação de sua produtividade econômica. A seguir, apresentamos um conjunto de problematizações acerca dos atuais desenvolvimentos da educação tecnocientífica na educação brasileira. Tal abordagem permitirá que estabeleçamos um olhar mais ampliado sobre os sentidos de conhecimento tecnocientífico evidenciados nos documentos curriculares para o ensino médio no Brasil contemporâneo. Em decorrência disso, ao final, apresentamos um conjunto de duas racionalidades bioeconômicas que atribuem produtividade aos investimentos nesta etapa da educação básica, a saber: o despertar talentos e popularização do acesso à ciência.

\section{a) Educação científica e o despertar de talentos}

Em aproximação com a analítica desenvolvida até este momento, importa assinalar que investimentos em educação tecnocientífica no ensino médio têm se constituído como um dos principais campos de investimento das atividades atuais da Unesco. 0 estímulo e as orientações a esse campo têm passado, em geral, por duas possibilidades de ação: ora contribuindo para o desenvolvimento econômico do País, ora desencadeando práticas que popularizem o acesso à ciência e à tecnologia como forma de despertar talentos. Em ambas as situações, podemos visibilizar o intenso e produtivo entrelaçamento entre as práticas educativas e o desenvolvimento econômico. Sob essa lógica, um determinado país opta por investimentos nessa área planejando resultados futuros ou, como afirma um importante documento daquele organismo internacional, citado anteriormente, realiza investimentos "à espera dos ovos de ouro". (Unesco, 2005, p. 4)

Conforme a inspiração dos recentes documentos publicados por essa organização internacional, as políticas e práticas educativas do Estado brasileiro tendem a atribuir centralidade a uma concepção de ensino médio que dialogue permanentemente com as mudanças no mundo do trabalho e com as inovações tecnocientíficas (Silva, 2011). Em geral, tais publicações tendem a posicionar 0 conhecimento como um recurso fundamental ao desenvolvimento econômico de uma nação na atualidade. Partem do entendimento de que um país que não prioriza a educação tende a ocupar uma posição de subalternidade no cenário da competitividade internacional ou de que a diferenciação entre países ricos e pobres na atualidade tem como fator principal a criação e a distribuição dos benefícios do saber científico. (Unesco, 1999; Unesco, 2003)

A condição de desigualdade no acesso ao saber científico indica que 
todos os países, além de buscarem investimentos para a consolidação de uma matriz científico-tecnológica, deveriam propiciar que os saberes sejam garantidos a todos mediante processos de democratização. Tal movimento implica uma ampliação das possibilidades de acesso à ciência, desencadeando um imperativo político de "ciência para todos", expressão que nomeia uma importante publicação da Unesco. Na medida em que a intenção passa por operar no eixo da democratização, a instituição escolhida pelas políticas para desencadear tal processo é a escola, aquela instituição com importantes serviços prestados em atividades de massa. Estudos como os de Alvarez-Uria (2002) evidenciam o modo pelo qual a instituição escolar se fez produtiva para o desenvolvimento "do espírito do capitalismo". Em um artigo publicado pela organização internacional intitulado "Ensino de Ciências: o futuro em risco", são enunciadas algumas das premissas políticas dessas práticas.

Se é indiscutível a importância da ciência e tecnologia para o desenvolvimento econômico e social do país, é preciso reconhecer que entre os condicionantes desse desenvolvimento estão uma educação científica de qualidade nas escolas; a formação de profissionais qualificados; a existência de universidades e instituições de pesquisas consolidadas; a integração entre a produção científica e tecnológica e a produção industrial; a busca de solução dos graves problemas sociais e das desigualdades. (Unesco, 2005, p. 2)

Com um prévio conjunto de investimentos, a publicação examinada privilegia a apresentação de alguns dos sentidos pelos quais a educação científica nas escolas pode contribuir para o desenvolvimento econômico e social de uma determinada região. Como indica o próprio título da publicação, o grande problema está no futuro colocado em risco, ou seja, de que com baixos investimentos em educação científica o país fique para trás na competitividade internacional. De forma mais enfática, o texto indica que "a ineficácia dos nossos sistemas de ensino na promoção de uma educação científica de qualidade tem um custo alto para o Brasil. Por um lado, diminui-se o número de profissionais nas áreas científicas e, com isso, perde-se em posição nos mercados competidores" (Unesco, 2005, p.4). Sob a perspectiva de despertar talentos, notamos que há uma tendência em posicionar a educação tecnocientífica a serviço do capitalismo contemporâneo.

A chave para reverter tais condições desfavoráveis, com base nessa concepção, estaria em investir na possibilidade de melhorar a qualidade da população. “Investir para constituir uma população cientificamente preparada é cultivar para receber de volta cidadania e produtividade, que melhoram as condições de vida de todo o povo" (Unesco, 2005, p. 2). Uma população 
cientificamente preparada seria produzida com investimentos na educação científica da escola básica, em especial em sua potencialidade para despertar talentos individuais. Acerca desse tópico, servindo-nos da abordagem de Fumagalli (2010), notamos os investimentos bioeconômicos em ação.

Em articulação com a publicação desses documentos pela Unesco, podemos notar como as temáticas da educação científica e da educação secundária começam a receber importantes investimentos articulados le consequentes reformas curriculares) nos países da América Latina no transcorrer da última década do século passado. Terigi (2007) mostra-nos como tais reformas curriculares da América Latina têm privilegiado o ensino médio. Ainda importa salientar que, conforme sinalizamos anteriormente, nessas diferentes modalidades, noções ligadas ao capitalismo contemporâneo e ao desenvolvimento científico-tecnológico têm orientado as políticas curriculares de nosso tempo, produzindo significativas ressonâncias para a constituição das subjetividades em nosso tempo.

\section{b) Educação tecnocientífica e a promoção de uma ciência para todos}

Fazendo um rápido inventário das orientações curriculares brasileiras na última década, não é difícil perceber a produtividade das inter-relações entre a ciência e a tecnologia na educação nacional. Ao fazer esse movimento, a intenção está em mostrar algumas recorrências dessas temáticas na atualidade, que, de certa forma, permitam produzir um breve diagnóstico das políticas científicas no ensino médio de nosso País. Nas Orientações Curriculares para o Ensino Médio (2006), ao tratar-se dos conhecimentos de biologia, mais especificamente ao explicitarem-se os encaminhamentos para as escolas organizarem seu projeto pedagógico, indica-se que a principal meta a ser buscada pela instituição escolar é "compreender e interpretar os impactos do desenvolvimento científico e tecnológico na sociedade e no ambiente" (Brasil, 2006, p. 20). 0 documento aponta que o objetivo acima se torna fundamental devido aos avanços dos estudos em genética e à grande biodiversidade do Brasil. Ao mesmo tempo que atribui centralidade a esses aspectos, o documento postula uma vinculação entre desenvolvimento científico e educação cidadã. "Todos devem aprender ciência como parte de sua formação cidadã, que possibilite a atuação social responsável e com discernimento diante de um mundo cada vez mais complexo". (Brasil, 2006, p. 21)

0 mesmo documento (Brasil, 2006), ao abordar os conhecimentos de física, é bem mais enfático ao tratar dos conhecimentos tecnológicos. 0 documento 
critica os livros didáticos por estes fazerem um uso simplesmente ilustrativo da tecnologia atual. "Deve-se tratar a tecnologia como atividade humana em seus aspectos prático e social, com vistas à solução de problemas concretos" (Brasil, 2006, p. 47). 0 documento evidencia como conceito delineador do ensino da disciplina no ensino médio a noção de "alfabetização científica e tecnológica". Tal noção objetivaria "que os alunos compreendam a predominância de aspectos técnicos e científicos na tomada de decisões sociais significativas e os conflitos gerados pela negociação política" (Brasil, 2006, p. 47). Para atingir tais condições, o documento propõe um ensino de física orientado por "projetos de aprendizagem". (Brasil, 2006, p. 53)

Assim, o que a física deve buscar no ensino médio é assegurar que a competência investigativa resgate o espírito questionador, o desejo de conhecer o mundo em que se habita. Não apenas de forma pragmática, como aplicação imediata, mas expandindo a compreensão do mundo a fim de propor novas questões e, talvez, encontrar soluções. Ao se ensinar Física devem-se estimular as perguntas e não somente as respostas a situações idealizadas. (Brasil, 2006, p. 53)

As referidas orientações curriculares, na apresentação dos conteúdos de matemática, enfatizam o uso da tecnologia como uma ferramenta e a exigência de um pensamento interdisciplinar. Destacando o uso da tecnologia, o texto curricular aponta duas perspectivas para esse objetivo: a capacitação para a utilização da tecnologia e esta como ferramenta de aprendizagem. Mais especificamente, segundo o documento, enfatiza-se “a matemática como ferramenta para entender a tecnologia e a tecnologia como ferramenta para entender a matemática". (Brasil, 2006, p. 87)

Considerando os desafios de um mundo em permanentes mudanças (científicas e tecnológicas, dentre outras), as orientações recomendam que os currículos do ensino médio devem primar pelo "trabalho interdisciplinar" (Brasil, 2006, p. 90). Para tanto, é sugerido como alternativa o "trabalho com projetos". O trabalho com projetos, além de operar a partir da resolução de problemas, promoveria interlocuções e aproximações com diferentes temáticas sociais.

O Relatório Pedagógico do Enem (Brasil, 2008), ao apresentar o modelo de avaliação, argumenta que "foi desenvolvido com ênfase na aferição das estruturas mentais com as quais se constrói continuamente o conhecimento e não apenas a memória". (Brasil, 2008, p. 37). 0 relatório justifica a escolha dessa concepção de conhecimento devido às intensas mudanças na sociedade contemporânea. Assim, o estudante deve "ser capaz de compreender o mundo 
em que vive, tal é a velocidade das mudanças sociais, econômicas, tecnológicas e do próprio acervo de novos conhecimentos com os quais se convive diariamente e que invadem todas as estruturas da escola". (Brasil, 2008, p. 37)

As rápidas mudanças a que estamos submetidos contemporaneamente também são utilizadas para justificar a ênfase na resolução de problemas. “Hoje, por exemplo, um conhecimento científico, uma tecnologia ensinada na escola é rapidamente substituída por outra mais moderna, mais sofisticada e atualizada, às vezes, antes mesmo que os alunos tenham percorrido um único ciclo de escolaridade" (Brasil, 2008, p. 38). O documento visibiliza que tais pressupostos devem orientar não apenas a organização da avaliação em larga escala, mas também encaminhar rápidas e profundas reformas dos sistemas de ensino que ofertam o ensino médio. Na própria acepção do texto curricular, "os novos tempos exigem um outro modelo educacional que esteja voltado para o desenvolvimento de um conjunto de competências e de habilidades essenciais, a fim de que crianças e jovens possam efetivamente compreender e refletir sobre a realidade, participando e agindo no contexto de uma sociedade comprometida com o futuro" (Brasil, 2008, p. 38). Enfim, percebemos nesse aspecto outra forma de intervenção bioeconômica na educação tecnocientífica, a perspectiva de popularização do acesso a esses saberes com vistas a melhorar as condições sociais e o potencial de competitividade do País.

\section{Considerações finais}

Ao longo do presente texto, produzimos um breve diagnóstico acerca das relações entre o desenvolvimento tecnocientífico e as políticas curriculares para o ensino médio. Partindo de uma abordagem sociológica, constatamos que a centralidade da referida temática está associada à emergência de uma "cultura-mundo", como assinalam Lipovetsky e Serroy (2011). Sob tais condições, percebemos a predominância de valores referentes a uma intensa articulação entre o individualismo, o mercado e a tecnociência. Nesse contexto, também podemos verificar uma ressignificação nas formas de intervenção do Estado, aproximando-se de modelos mistos, delineados por parcerias e heterarquias (Ball, 2013a). As políticas curriculares desencadeadas nesse período, de acordo com a literatura revisada, tendem a privilegiar uma concepção de conhecimento, caracterizada pelo instrumentalismo, expressa na formulação "aprender para ganhar, conhecer para competir". (Lima, 2012)

A leitura sociológica que produzimos para o estudo das atuais políticas curriculares para o ensino médio permitiu-nos também examinar o intenso 
entrelaçamento entre tais condições e a promoção de políticas de educação tecnocientífica. Tal como o paradoxo evidenciado por Krawczyk (2011) nas políticas educacionais para o ensino médio, entre democratização do acesso e ampliação da competitividade econômica, em nossa análise deparamo-nos com situação semelhante. As políticas de educação tecnocientífica para o ensino médio potencializam estratégias de intervenção bioeconômica na população brasileira (Fumagalli, 2010), ora enfatizando uma capitalização dos talentos, ora assumindo uma pauta de qualificação das condições formativas, enfatizando possibilidades de popularização da ciência. Este diagnóstico serve como ponto de partida para novos estudos críticos e outras políticas curriculares, que superem a gramática da intervenção bioeconômica e que possam apostar no potencial formativo dos conhecimentos científicos, associando-os à promoção de modos de vida democráticos.

\section{Referências:}

ALVAREZ-URIA, Fernando. A escola e o espírito do capitalismo. In: COSTA, Marisa (Org.). Escola básica na virada do século: cultura, política e currículo. $3^{a}$ ed. São Paulo: Cortez, 2002. pp. 131-144.

BALL, Stephen. Novos Estados, nova governança e nova política educacional. In: APPLE, Michael; BALL, Stephen; GANDIN, Luís Armando (Orgs.). Sociologia da educação: análise internacional. Porto Alegre: Penso, 2013a. pp. 177-189.

BALL, Stephen. Aprendizagem ao longo da vida, subjetividade e a sociedade totalmente pedagogizada. Educação, Porto Alegre, PUCRS, v. 36, n. 2, pp. 144155, maio-ago. 2013b.

BALL, Stephen. New philanthropy, new networks and new governance in education. Political Studies, v. 56, n. 2, pp. 747-765, jun. 2008.

BAUMAN, Zygmunt. Modernidade líquida. Rio de Janeiro: Jorge Zahar, 2001.

BRASIL. Orientações curriculares para o Ensino Médio: Ciências da Natureza, matemática e suas tecnologias. Brasília: Ministério da Educação, 2006.

BRASIL. Exame Nacional do Ensino Médio (ENEM): Relatório Pedagógico 2007. Brasília: INEP, 2008.

BRASIL. Programa Ensino Médio Inovador: documento orientador. Brasília: Ministério da Educação, 2009.

BRASIL. Diretrizes Curriculares Nacionais para o Ensino Médio. Brasília: Ministério da Educação, 2012.

BRASIL. Pacto Nacional pelo Fortalecimento do Ensino Médio - caderno I, etapa 1. Brasília: Ministério da Educação, 2014. 
CASTELLS, Manuel. Estado-rede: a possibilidade do Estado na sociedade informacional. São Paulo: Paz e Terra, 1999.

CORSANI, Antonella. Elementos de uma ruptura: a hipótese do capitalismo cognitivo. In: COCCO, Giuseppe.; GALVÃO, Alexander; SILVA, Gerardo (Orgs.) Capitalismo cognitivo: trabalho, redes e inovação. Rio de Janeiro: DP\&A, 2003. pp. 15-32.

FOUCAULT, Michel. Nascimento da Biopolítica. São Paulo: Martins Fontes, 2008. FUMAGALLI, Andrea. Bioeconomía y capitalismo cognitivo: hacia un nuevo paradigma de acumulación. Madrid: Traficantes de Sueños, 2010.

GIDDENS, Anthony. As consequências da modernidade. São Paulo: Ed. da Unesp, 1991.

KRAWCZYK, Nora. Reflexão sobre alguns desafios do Ensino Médio no Brasil Hoje. Cadernos de Pesquisa, São Paulo, Fundação Carlos Chagas, v. 41, n. 144, pp. 752-769, set.-dez. 2011.

LIMA, Licínio. Aprender para ganhar, conhecer para competir: sobre a subordinação da educação na "sociedade da aprendizagem". São Paulo: Cortez, 2012.

LIPOVETSKY, Gilles. Os tempos hipermodernos. São Paulo: Barcarolla, 2004. LIPOVETSKY, Gilles; SERROY, Jean. A cultura-mundo: resposta a uma sociedade desorientada. São Paulo: Companhia das Letras, 2011.

LYOTARD, Jean-François. A condição pós-moderna. $12^{\mathrm{a}}$ ed. Rio de Janeiro: José Olympio, 2009.

MARAZZI, Christian. Biocapitalismo: a vida no centro do crescimento econômico. IHU On Line, São Leopoldo, Instituto Humanitas, n. 301, pp. 10-11. 2009.

MOEHLECKE, Sabrina. 0 ensino médio e as novas diretrizes curriculares nacionais: entre recorrências e novas inquietações. Revista Brasileira de Educação, Rio de Janeiro, Anped, v. 17, n. 49, pp.39-58, jan.-abril. 2012.

POPKEWITZ, Thomas. Uma perspectiva comparativa das parcerias, do contrato social e dos sistemas racionais emergentes. In: TARDIF, Maurice; LESSARD, Claude (Orgs.). O ofício de professor: história, perspectivas e desafios internacionais. 4a ed. Petrópolis: Vozes, 2011. pp. 234-254.

POPKEWITZ, Thomas. Estudios curriculares y la historia del presente. Profesorado: revista de currículum y formación del profesorado, Granada, Universidad de Granada, v. 14, n. 1, pp. 355-370, abril. 2010.

SENNETT, Richard. A cultura do novo capitalismo. São Paulo: Record, 2006.

SILVA, Roberto Rafael Dias da; SILVA, Rodrigo Manoel. Educação e cultura nas políticas de escolarização contemporâneas: um diagnóstico crítico. In: ROSA, Geraldo; PAIM, Marilane (Orgs.). Educação Básica: políticas e práticas pedagógicas. Campinas: Mercado de Letras, 2012. pp. 15-42. 
SILVA, Roberto Rafael Dias da. Políticas de escolarização e governamentalidade nas tramas do capitalismo cognitivo: um diagnóstico preliminar. Educação e Pesquisa, São Paulo, USP, v. 39, n. 3, pp. 689-704, jul.-set. 2013.

SILVA, Roberto Rafael Dias da. A constituição da docência no Ensino Médio no Brasil contemporâneo: uma analítica de governo. 2011. 215f. Tese (Doutorado em Educaçãol - Programa de Pós-Graduação em Educação, Universidade do Vale do Rio dos Sinos, 2011.

SILVA, Roberto Rafael Dias da. 0 ensino médio no Brasil contemporâneo: problematizações investigativas ao campo do currículo. In: NICOLAY, Deniz; VOLTOLINI, Caroline; CORÁ, Elsio. (Orgs.). Educação Básica e práticas pedagógicas: licenciaturas em debate. Passo Fundo: Ed. Universidade de Passo Fundo, 2012. pp. 37-54.

SIMONS, Maarten; MASSCHELEIN, Jan. 'Se nos hace creer que se trata de nuestra libertad': notas sobre la ironía del dispositivo de aprendizaje. Pedagogía y Saberes, Bogotá, UPN, n. 38, pp. 93-102, set.-dez. 2013.

TERIGI, Flavia. Los cambios en el currículo de la escuela secundária: por qué san tan dificiles?. Revista Prelac, pp. 158-165, 2007.

UNESCO. Ensino de Ciências: o futuro em risco. Edições Unesco, maio, pp. 1-5, 2005.

UNESCO. A ciência para o século XXI: uma nova visão e uma base de ação. Brasília: Unesco, 2003.

UNESCO. Declaração sobre a ciência e o uso do conhecimento científico. Budapeste, $1^{\circ}$ de julho de 1999.

Recebido em julho de 2014 Aprovado em dezembro de 2014

Roberto Rafael Dias da Silva é doutor em educação pela Universidade do Vale do Rio dos Sinos e professor do Programa de Pós-Graduação em Educação da Universidade Federal da Fronteira Sul, Campus Chapecó/SC. E-mail: robertosilvaQuuffs.edu.br 